\title{
El Catálogo General del Patrimonio Histórico Andaluz en la vega de Antequera y Archidona
}

De los 15 municipios que dibujan el territorio que conforma la vega de Antequera y Archidona, 12 están afectados en su totalidad y tres parcialmente.

Los 43 bienes patrimoniales que se encuentran en esta vega pertenecen la mayoría al municipio de Antequera (28), hecho que se explica por dos motivos principales: la amplitud territorial y la importancia que tuvo y ha tenido dicho municipio a lo largo de la historia, gracias a su situación estratégica como vía de comunicación entre la alta y la baja Andalucía.

Si clasificamos los 43 bienes por la figura legal que les da protección, nos encontramos que la gran mayoría (41) son Bienes de Interés Cultural (BIC), frente a los dos de Catalogación General. De los BIC, la tipología jurídica que destaca es la de Monumento (23), seguida por la Zona Arqueológica (16) y, por último, los Conjuntos Históricos de Antequera y Archidona.

En los últimos dieciocho meses el Servicio de Protección del Patrimonio Histórico de la Dirección General de Bienes Culturales ha propiciado, en este territorio, la protección de varias zonas arqueológicas, testigos del poblamiento desde época prehistórica.

Uno de los expedientes más destacable en la vega de Antequera y Archidona es el denominado Ámbito arqueológico de los Dólmenes de Antequera, inscrito en el Catálogo General del Patrimonio Histórico Andaluz (CGPHA) como Bien de Interés Cultural, tipología
Zona Arqueológica, el 27 de enero de 2009, y el cual extiende su protección a un territorio donde coexisten cinco bienes diacrónicos y de diferente naturaleza, que comparten un paisaje y un entorno común: Dolmen de Menga, Dolmen de Viera, Dolmen de El Romeral, yacimiento del Cerro Marimacho o Cerro de Antequera, y yacimiento de Carnicería de los Moros o Villa romana de Antequera.

Desde el punto de vista de la protección, los tres dólmenes tuvieron su reconocimiento como bienes patrimoniales ya desde el siglo XIX. La Cueva de Menga fue a través de la Real Orden de 1 de junio de 1886 que la declaró Monumento Nacional. Posteriormente se ratifica mediante Real Decreto de 12 de julio de 1923 en la que se reconoce también la importancia de la Cueva Chica o de los Hermanos Viera. Años más tarde, en 1931, se declara con el mismo carácter la Cueva de El Romeral.

Con fecha 17 de marzo de 2009, se inscribe en el CGPHA como Bien de Interés Cultural, Zona Arqueológica, un poblado ibero claramente romanizado, El Cerro de los Castillones (Campillos). Se trata de uno de los asentamientos paradigmáticos de los cambios en la organización de las sociedades prerromanas.

Más tarde, con fecha de 1 de diciembre de 2009, se protegió como BIC Zona Arqueológica el yacimiento denominado Las Capacheras (Archidona, Málaga), asentamiento fortificado u "oppidum", que cierra las defensas de época ibérica por el noreste de la provincia de Málaga.

Por último, el Decreto 63/2010, de 16 de marzo, inscribe en el Catálogo General del Patrimonio Histórico de Andalucía como Bien de Interés Cultural, tipología Zona Arqueológica, la Necrópolis protohistórica de la Noria, en el término municipal de Fuente de Piedra. Esta necrópolis se desarrolla en dos grandes periodos cronológicos, periodo protohistórico y periodo romano, con diferentes tipos de enterramientos.

Con estas actuaciones administrativas se ha querido distinguir la vega de Antequera y Archidona como un territorio de gran interés para el conocimiento de la prehistoria y protohistoria en Andalucia, importancia arqueológica que se une al sustancial legado arquitectónico de los siglos XVI al XVIII patente en la comarca.

El Catálogo General del Patrimonio Histórico Andaluz está abierto a la consulta pública en la página web de la Consejería de Cultura, dentro del área de Bienes Culturales: http://www.juntadeandalucia.es/cultura

Olga Viñuales Meléndez Alfonso Montejo Ráez Servicio de Protección del Patrimonio Histórico Dirección General de Bienes Culturales

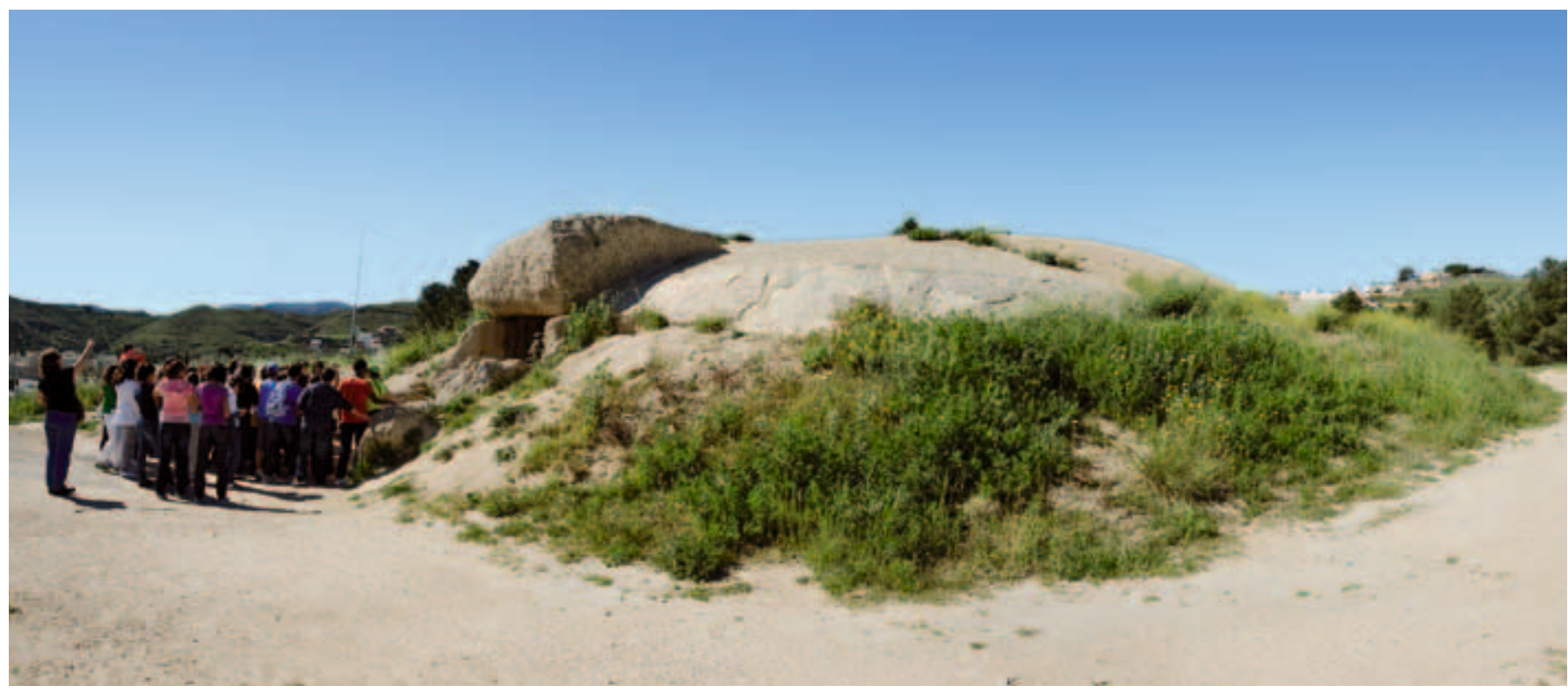



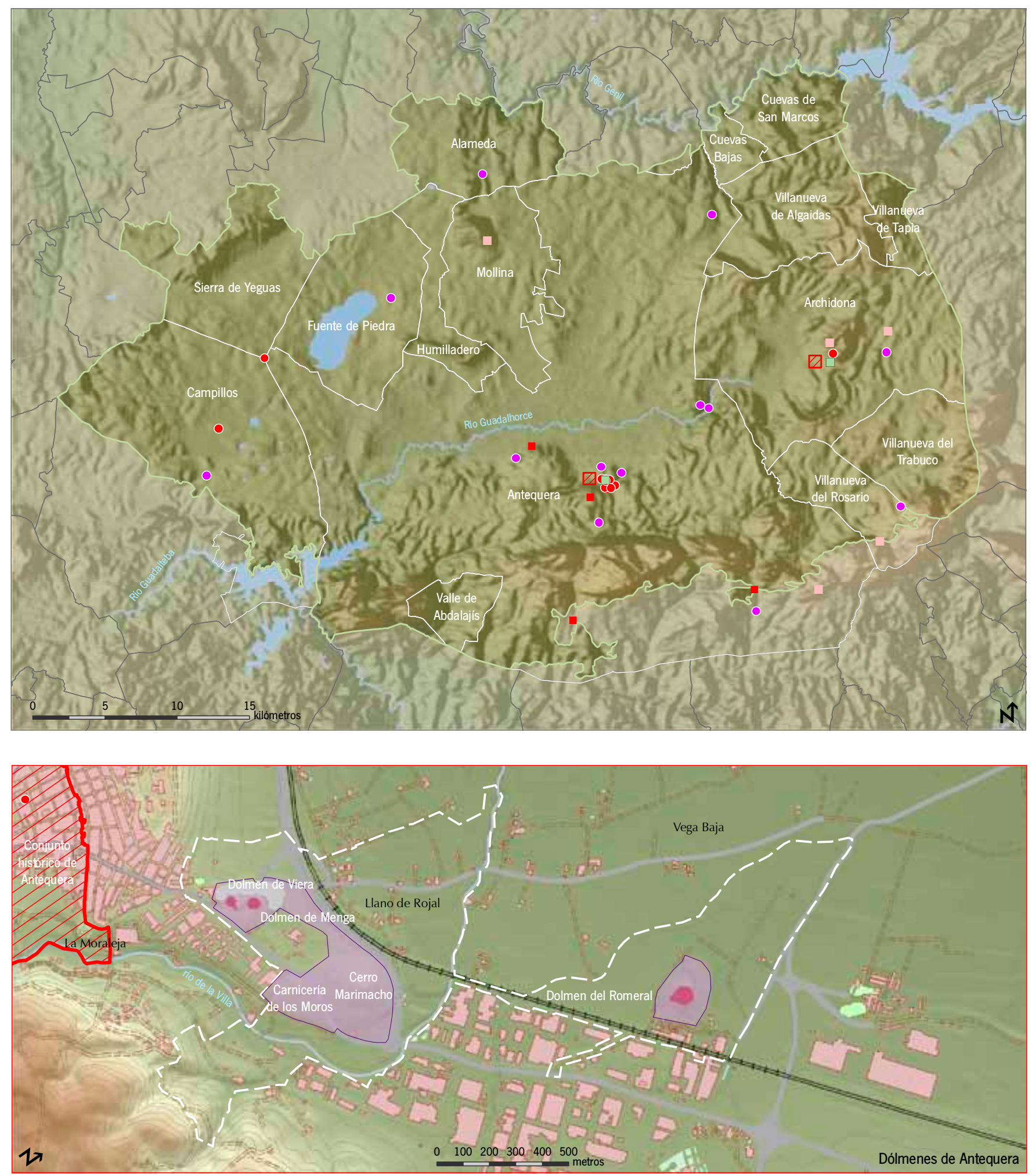

\begin{tabular}{|c|c|c|}
\hline $\begin{array}{l}\text { Bien de Interés } \\
\text { Cultural }\end{array}$ & $\begin{array}{l}\text { - Monumento } \\
\text { Arquitectura militar }\end{array}$ & $\begin{array}{l}\square \text { Conjunto Histórico } \\
\text { - Zona Arqueológica }\end{array}$ \\
\hline & Arte rupestre & Entorno \\
\hline
\end{tabular}

Bien de Catalogación General
El Catálogo General del Patrimonio Histórico Andaluz en las Vegas de Antequera y Archidona

Cartografia base: Datos Espaciales de Andalucia 1:100.000 (2009), Modelo Digital del Terreno de Andalucia (2005), y Mapa Topográfico de Andalucia 1:10.000 vectorial (2002), Instituto de Cartografía de Andalucía 